\section{The drivers of omni-channel shopping intention: a case study for fashion retailing sector in Danang, Vietnam}

Drivers of omni-channel shopping intention

Thi Hieu Hanh Truong

\author{
The Faculty of Ecommerce, University of Economics, The University of Danang,
} Da Nang, Vietnam
Received 28 May 2020 Revised 6 August 2020 19 August 2020 Accepted 20 August 2020

\begin{abstract}
Purpose - The purpose of this paper is to look into the mechanism in which customers involve themselves in omni-channel retail setting and use its advantages.

Design/methodology/approach - Via an empirical analysis through surveying customers, this paper assesses and confirms the drivers of omni-channel shopping intention within the context of fashion retailing sector in Danang.

Findings - The findings highlight the significance of customer perception of research shopping (including showrooming and webrooming) behaviours, compatibility and risk to their intention towards omni-channel shopping, implying profound understanding of designing effective omni-channel retailing strategy.

Originality/value - From a theoretical perspective, comprehending customer perception of the omni-channel concept has emerged as an important theme in recent literature as well as in practitioners' reports. Hence, the meaningful contribution of this study is the involvement in the attractive steam of study. From a managerial perspective, this study could offer guidance to retailers or managers about developing a successful omnichannel strategy from a customer point of view.
\end{abstract}

Keywords Omni-channel shopping intention, Perceived value of showrooming, Perceived value of webrooming, Perceived compatibility, Perceived risk

Paper type Research paper

\section{Introduction}

The retailing paradigm has been changing significantly from mono- to multi-channel and even omni-channel model over the past two decades, thanks to the acceleration of information technology (Christensen and Raynor, 2003). These developments not only bring seamless and unified shopping experiences across channels for customers but also help retailers increase touchpoints, meet customers' needs immediately, then yield revenues (Ailawadi and Farris, 2017). Whereas in-store sales still consist of major retail sales, exploiting new channels as well as blending online and offline channels are key strategies that have played the greater role in achieving competitive advantages for enterprises (Business Insider Intelligence, 2017). In fact, the aim of multi-channel retailing is to reach different customer segments with various needs as well as preferences through obtaining different channels' specific advantages.

\section{JEL Classification - M31, O33}

(C) Thi Hieu Hanh Truong. Published in Journal of Asian Business and Economic Studies. Published by Emerald Publishing Limited. This article is published under the Creative Commons Attribution (CC BY 4.0) licence. Anyone may reproduce, distribute, translate and create derivative works of this article (for both commercial and non-commercial purposes), subject to full attribution to the original publication and authors. The full terms of this licence may be seen at http://creativecommons.org/licences/by/4.0/ legalcode

This work was supported by the University of Economics, The University of Danang, belonged to project of T2020-04-55.

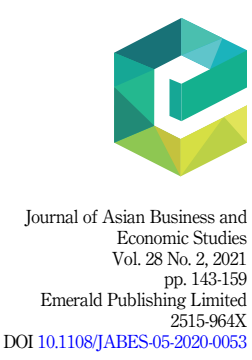


JABES

28,2

144

Meanwhile, instead of having its own logistic system for different channels, each of the channels in an omni-channel setting is not concerned with customer retention by itself anymore, but leverage its advantages to serve every users to assist their final orders anywhere any time without concern about selected channels (Zhang et al., 2018). Briefly, the differences between these two forms of retail lie in three main aspects, including consumer experiences, operation mode and implementation objectives.

Being the dominant strategy in most markets, unsurprisingly, the omni-channel context has attracted great attention as well as been ranked third on important topic in service research (Ostrom et al., 2015). Specifically, major studies on omni-channel retailing typically investigate from a retailer perspective such as retailers' activities of channel integration (Zhang et al., 2018), channel integration quality (Shen et al., 2018), omni-channel supply chain management (Liu et al., 2020). When it comes to studies on a consumer view of point, a few works concentrate on customer behaviours in omni-channel setting such as channel selection intention (Xu and Jackson, 2019), omni-channel customer experience (Kazancoglu and Aydin, 2018) and omni-channel shopping intention (Shi et al., 2020). Obviously, it is very crucial for omni-channel practitioners to comprehend the mechanism in which customers involve themselves in an omni-channel retail setting and use its advantages, as this could help managers design effective channel strategies. Nevertheless, researches into this topic are relatively limited and needed to continue to discuss. Hence, with respect to the emerging field of omni-channel retailing, this study explores the primary question of "what are determinants of customers' intention to adopt omni-channel method for shopping within the context of fashion retail sector in Danang". This study's main contribution lies on the fact that, to the best of my knowledge, this is one of few researches assessing the contributory factors to customers' shopping intention among the context of omni-channel retail, developed from the innovation diffusion theory (IDT) and the prospect theory. Particularly, this research considers customers' perception of research shopping behaviours (including showrooming and webrooming behaviours), the compatibility across retail channel as well as risks in omnichannel setting. This study is not only expected to bring managers with a profound understanding of components driving customers' omni-channel shopping intention, but it also complements the literature by investigating the relations between mentioned research variables and validating the theoretical framework in Vietnam, from academia perspective. The fashion retailing sector is chosen as the research context because it is one of the few sectors that have implemented the earliest omni-channel retailing forms in Vietnam, having been shown to be one of the sectors with great growth prospects when continuously achieving stable growth rates in recent years. Hence, it is meaningful and necessary to conduct researches on customer intention to omni-channel shopping. Consequentially, the research expects to bring both scientific and practical contributions, assisting retail managers to suggest effective solutions to managing retailing channels.

\section{Literature review}

\subsection{Omni-channel retailing and omni-channel shopping intention}

Emerging as a common strategy in the new era of retail industry, omni-channel retailing has attracted attention not only in the academia but also in the real-world practices. Particularly, Brynjolfson et al. (2013) define this concept as a business model offering seamless and unified experiences to customers without differences between offline and online shopping. In a same vein, Bernon et al. (2016) mention a synchronized operating model in which a firm can align all channels with not only the presentation of a single face to customers but also a consistent way of doing business. From a managerial perspective, Verhoef et al. (2015) consider omni-channel management to be the synergetic management of varied available channels as well as customers outpoints by which the performance over channels and customer experiences 
across channels are optimized. Obviously, there is a consistency of this concept in literature, making this area of research advantageous to study.

Regarding omni-channel shoppers, Sopadjieva et al. (2017) consider these people as keen users of not only retailers' channels but also touchpoints. Verhoef et al. (2015) claim that retailers' processes of full channel integration allow consumers simultaneously and interchangeably utilize various channels and touchpoints to enjoy seamless omni-channel shopping experiences. Particularly, over their searching as well as making decisions, customers can integrate the full range of products, orderings, delivery services and return policies. Consumers can use simultaneously retailers' currently available channels for seeking information; adopt purchase channel forms, including physical stores, catalogues, mobile apps, website, social network and more recent blended channels like buy online - pick up in store or buy in store - home delivery; apply return channel forms like return product to retail store, ship to retailer's warehouse manufacturer's factory, etc. In this context, it is reasonable to consider omni-channel shopping intention as customers' intention to adopt this method for shopping.

\subsection{Research shopping phenomenon}

Many researchers agree that "research shopping behaviour" is a predominant topic in the literature on the new era of retail, especially in the field of multichannel customer management (Verhoef et al., 2007; Mau et al., 2015). Noticeably, the definition of this concept is quite clear and widely accepted, in which case, the research shopping phenomenon is defined as customers' inclination towards searching information on one channel and then purchasing products via another (Verhoef et al., 2007; Pauwels et al., 2011; Nesar et al., 2016). Research shopping behaviour comprises showrooming and webrooming that are considered as prominent shopping trends of omni-channel shoppers (Kang, 2018). While showrooming is described as the practice in which customers search information offline and subsequently buy products online, webrooming is mentioned as the customer practice of searching information online and then purchasing products offline (Flavián et al., 2016).

There are three main reasons for research shopping behaviours in omni-channel setting that is found in literature. They are shortage of channel lock-in, attribute driven decisionmaking, cross channel synergy (Verhoef et al., 2007). Besides, the psychological characteristics of customers (like price sensitivity, brand loyalty, innovativeness, etc.) are also regarded as a reason for research shopping behaviours (Kumar and Venkatesan, 2005). On other hand, regarding the consequence of this phenomenon, it must agree that there is a dilemma in the literature. Particularly, whereas research shopping behaviours could benefit customers over the process of searching and making decision, this could make managing and maintaining customers more difficult because customers at the pre-purchase and purchase phases may not be the same (Nunes and Cespedes, 2003). By contrast, many scholars such as Kumar and Venkatesan (2005), Chiou et al. (2012) argue that it is very important for retailers to recognize this phenomenon because it creates a great impact on the sales revenues deriving from various channels. In general, with the dramatic shift in research shoppers' behaviours in recent years, it is reasonable to require a comprehensive understanding of the omni-channel strategy in literature from a consumer perspective.

\section{Research framework and hypotheses}

A research framework was proposed in this study to explore the drivers of omni-channel shopping intention, as illustrated in Figure 1. In accordance with the work of Kang (2019) and Shi et al. (2020), perceived value of showrooming and webrooming; perceived compatibility and perceived risk are hypothesized to impact consumers' intention to shop utilizing

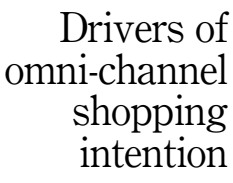




\section{JABES \\ 28,2}

\section{6}

Figure 1.

Proposed research framework

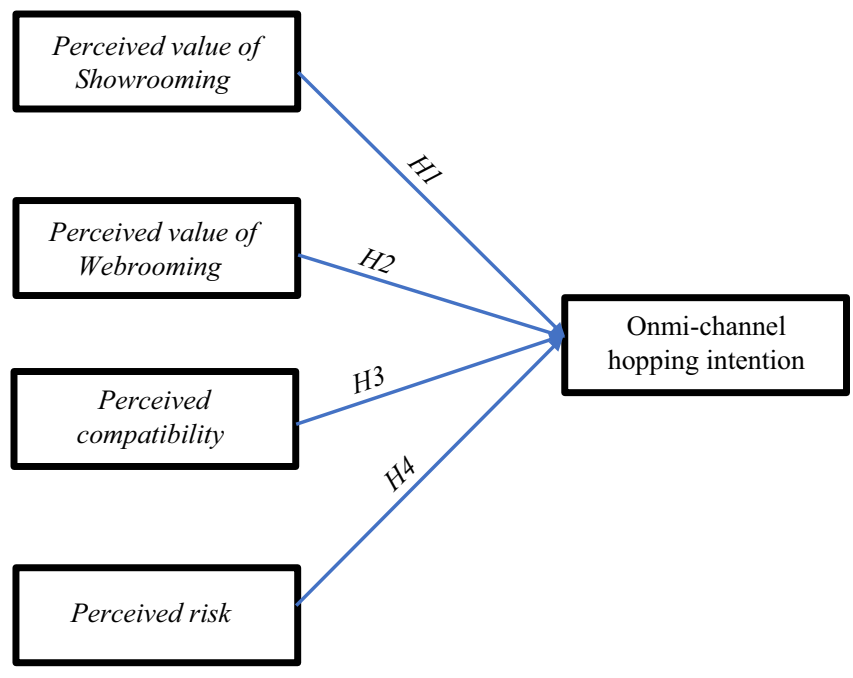

omni-channel method. As a result, the theoretical model in this study was developed based on the IDT of Rogers (2010) and the prospect theory of Kahneman and Tversky (1979).

Specifically, the former mentions an innovation's communication through particular channels over time among members from a social system in which innovation refers to a practice, object or idea perceived as new by either an individual or another unit of adoption (Rogers, 2010). Dwivedi et al. (2019) claim that individual decisions on adoption or rejection of an innovation are relied upon both individuals' perceptions of and beliefs about the innovation. Interestingly, the process of individuals' innovation decision involves three stages: perceptions before innovation adoption, perceived characteristics of adopting the innovation and adoption or rejection of the innovation, at Rogers' suggestion. Logically, within the context of this study, omni-channel shopping intention can be regarded as the result of perceived characteristics of adopting omni-channel shopping. The logic behind this explanation stems from the assumption of Carroll and Guzmán (2015) that omnichannel shopping is considered to be an innovative and emerging form of shopping. As a result, in a similar vein of prior researches, perceived risk and perceived compatibility are chosen as essential innovation characteristics, having linkages with omni-channel shopping intention.

On the other hand, the latter - the prospect theory - emphasizes the perspective of a value maximization to forecast individual decisions behaviours with unknown or undecided situation (Kahneman and Tversky, 1979). Within the context of a retail environment, values perceived by customers during the purchasing decision process can influence their intention behaviour or behaviour. Particularly, in this study, the perceptions of customers about values of showrooming and webrooming can be used to predict their behaviour over purchase and post-purchase periods.

\subsection{Perceived value of research shopping and omni-channel shopping intention}

Interestingly, the influence of perceived value by customers and shopping intention has been examined in many literatures from various perspectives, and most of them accept the significantly positive relation between these two variables (Song et al., 2019). Specially, Pan et al. (2009) regard perceived value as the most direct motivation for customers' intention 
behaviour. In a similar vein, not only confirm this linkage, Shapiro et al. (2019) also suggest a partial mediating role of perceived value in explaining customers behaviour. In the context of omni-channel, research shopping behaviours of omni-channel shoppers relate seeking information on one channel and subsequently purchasing products or services on other channels. Although the literature on the effects of perceived value of showrooming and webrooming on omni-channel shopping intention is scare, Kang's (2019) research is the latest research providing evidences for this relation. Hence, this study accepts Kang's findings as well as agree with arguments in prior research to suggest hypotheses of $\mathrm{H} 1$ and $\mathrm{H} 2$ as the following. It is reasonable to assume that if customers' value perception of showrooming and webrooming is positive, it will increase the probability of their intention to adopt omnichannel shopping method.

H1. Perceived value of showrooming is positively associated with omni-channel shopping intention.

H2. Perceived value of webrooming is positively linked with omni-channel shopping intention.

\subsection{Perceived compatibility and omni-channel shopping intention}

Perceived compatibility is accepted as one of the innovation characteristics in IDT (Kim et al., 2017; Shi et al., 2020). Moore and Benbasat (1991), Aljabri and Sohail (2012) define this concept as the consistent level of an innovation perceived with potential adopters' existing values, needs and past experiences. In the omni-channel environment, the past shopping experience of customers with particular channels can be used as a predictor for their intention to adopt omni-channel shopping, at Shen et al.'s (2018) suggestion. Empirical results of Shi et al. (2020) can support this argument. It comes as no surprises to confirm that customers' perception of compatibility should be regarded as a key antecedent of users' intention for technology adoption. Specifically, Limayem et al. (2007) concludes customer evaluation of the focal technology from their past habits of utilizing specific technology because they are less likely to depend upon conscious judgement with the higher degree of habits. Thus, in the same vein of extant literature, this study proposes H3 as the following:

H3. Perceived compatibility is positively related to omni-channel shopping intention.

\subsection{Perceived risk and omni-channel shopping intention}

Like perceived compatibility, perceived risk is also an essential innovation characteristic but presented as a barrier in adopting omni-channel retail. In retailing literature, Falk et al. (2007) offer evidences for the mediating role of perceived risk of new channel in the relation between current channel attribute and customers' new channel adoption decision. Similarly, within the context of omni-channel retailing environment, Herhausen et al. (2015) confirm a significant impact of shopping risks across channels on the firm's omni-channel image. In general, to clarify the effects of perceived risk on individuals' innovation adoption, many researchers attempt to illustrate some type of risks consumers can be aware of when reaching various channels (like financial- or performance-related risks) with different research contexts such as mobile payment (De Kerviler et al., 2016), online banking (Alalwan et al., 2018). As a result of following the logic of previous studies, it is appropriate to expect that the less-risk customers perceive over the process of omni-channel shopping, the more probability they intend to employ this method to experience its benefits. Accordingly, $\mathrm{H} 4$ is suggested as the following:

H4. Perceived risk is negatively related to omni-channel shopping intention.
Drivers of
omni-channel
shopping
intention 
JABES

28,2

148

\section{Research methodology}

\subsection{Sample and data collection}

An online survey method was adopted in this study to assess the research framework and test hypotheses. The sample selected were consumers over the age of 18, who are used to shop more than one channel at retailers of fashion items and accessories (e.g. two or more channels among traditional channels, websites, social networks, mobile applications, etc.) within a period of three months from the date of purchase to the date of sample collection.

Initially, a pilot survey was conducted on 20 consumers with the purpose of adjusting the indicators to suit the shopping habits of Vietnamese. After that, an official survey with 265 consumers, conducted a sample collection by taking an online survey.

Next, 257 valid questionnaires were obtained from 265 responses collected in total, after excluding invalid questionnaires that have the same answer for most of the questions in an effort to clean data. The validity rate is nearly $96.98 \%$. Table 1 below presents participants' profile.

\subsection{Measurement and questionnaire design}

All constructs' measurements in this research were employed from pervious researches with minor adaptation to match the current research context. Specifically, perceived value of showrooming and webrooming scales was adopted from Voss et al. (2003) and Toijb and Tsarenko (2012). Meanwhile, perceived of compatibility and perceived of risk were measured with items adopted from Moore and Benbasat (1991) and Van der Heijden et al. (2003), respectively. Finally, measurement items for omni-channel shopping intention were modified from Wong Jeong et al. (2009) and Shi et al. (2020) to fit the context of the fashion retailing sector. All items were measured by using a five-point Likert scale that ranges from $1=$ strongly disagree to $5=$ strongly agree).

Obviously, a well-designed questionnaire could bring valuable data besides reaching target audiences. This study uses the filter question to determine if a respondent is qualified or experienced enough to conduct the survey ("Over the last 3 months, have you shopped more than two channels at retailers of fashion items and accessories, for example, two or more channels among physical stores, websites, social networks, mobile applications, ecommerce platforms", etc.). The survey was conducted via a Google Form in which the link was introduced on Fanpages or Groups Facebook of fashion retailers having traditional stores in Danang, Vietnam, as well as implementing multi-channel retailing through websites, social networks, e-commerce platforms, mobile applications (e.g. OLV Danang, NEM Fashion Danang, Pantio Danang, Elise Danang, etc.). Simultaneously, thanks to the collaboration of these retailers, customers who visited clothes stores or showrooms could be asked whether

\begin{tabular}{llrr}
\hline Characteristics & Observations & Frequency & $\%$ \\
\hline \multirow{2}{*}{ Gender } & Male & 73 & 28.40 \\
& Female & 184 & 71.60 \\
& $18-24$ & 78 & 30.35 \\
& $25-34$ & 134 & 52.14 \\
& $35-44$ & 32 & 12.45 \\
Personal income per month in VND & $\geq 45$ & 13 & 5.06 \\
& Below VND3m & 46 & 17.90 \\
& From VND3m to below VND5m & 98 & 38.13 \\
& From VND5m to below VND10m & 81 & 31.52 \\
& Above VND15m & 32 & 12.45
\end{tabular}

Note(s): $N=257$ 
they could participate in the survey by portable devices such as tablets, smart phones at that time. The questionnaire structure includes two main parts, in which the first one is questions about demographics (gender, age, income) and multi-channel shopping experiences-relevant questions (e.g. Do you often seek information offline and subsequently purchase products online? Do you often seek information online and subsequently purchase product in the local stores?), while the second one is questions about research variables (perceived value of showrooming, perceived value of webrooming, perceived compatibility, perceived risks, omni-channel shopping intention).

\subsection{Data analysis}

The partial least squares (PLS) method implemented in SmartPLS 3.0 is used in this study to test the proposed research model for some reasons. Firstly, PLS-structural equation modelling (PLS-SEM) analysis is utilized for developing theories in exploratory research (Hair et al., 2014), which is appropriate for the exploratory nature in this study. Indeed, to the best of my knowledge, there is no prior study assessing the framework of these variables in Vietnam as well as on the world. Secondly, this analysis puts less restrictions not only on data distribution but also on measurement scales (Chin et al., 2003). Moreover, a two-step analytical approach is adapted in this study, at Anderson and Gerbing's (1988) suggestion. Specifically, to ensure the appropriate validity as well as reliability of the constructs, measurement model is first analyzed, followed by estimating the structural model to assess both the model's theoretical explanatory power and the hypothesized relationships' significance levels.

\section{Empirical results}

\subsection{Respondents profile}

A majority of respondents in this research were female $(71.60 \%)$, with the overwhelming dominance in young age groups: $18-24(30.35 \%)$ and $25-34(52.14 \%)$. The research data also highlight the differences between middle classes (from VND3m to below VND10m) with $69.65 \%$ and the other two groups with $30.35 \%$. These things reflect relatively the reality of buying fashion items in Danang, Vietnam.

Moreover, concerning respondents' multi-channel shopping experiences, the number of customers who often check out products at physical stores and then buy them online (showroomers) is larger than that of examining products via online channels and subsequently purchasing them at the local stores (webroomers) $(50.20 \%, 31.13 \%$, respectively). Meanwhile, there are 48 out of 257 respondents believing that they frequently do both types of research shopping behaviours (showrooming and webrooming) (18.68\%). Obviously, showrooming is more popular than webrooming among the multi-channel shopping environment. Interestingly, from the empirical results, the phenomenon of research shopping is more prevalent among customers who are in the age groups of 18-34 by comparison with other age groups.

\subsection{Measurement model}

To test the reliability of the scales, this study applied the recommendations of Hair et al. (2016), including Cronbach's alpha, composite reliability (CR), convergent validity and discriminant validity.

The results show that the scales achieve internal consistency when Cronbach's alpha and $\mathrm{CR}$ are greater than 0.7 . Then, to improve reliability, outer loadings validity less than 0.7 , such as PVS1 (0.688), PVS3 (0.679), PVW3 (0.150), PVW6 (0.595), PVW7 (0.632), will be omitted. Moreover, each construct's average variance extracted (AVE) value is all greater than 0.50 .

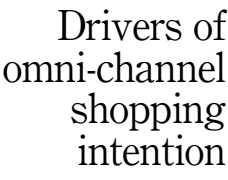


JABES

28,2

150

Table 2 below presents the results of assessing the validity and reliability of research's measurements.

As mentioned above, to examine the discriminant validity of research constructs, Fornell and Larcker (1981) criterion is employed. Table 3 shows the results of the Fornell and Larcker condition test. All the square root of AVE values, which are on the diagonal, are greater than the corresponding correlation coefficients. Hence, the discriminant validity is satisfactory in this research.

\subsection{Structural model}

The criteria for evaluating the quality of PLS-SEM model as well as the hypothesis testing steps in this study are based on the recommendations of Hair et al. (2017).

\begin{tabular}{|c|c|c|c|c|}
\hline Constructs and items & Loading & $\begin{array}{l}\text { Cronbach's } \\
\text { alpha }\end{array}$ & $\mathrm{CR}$ & AVE \\
\hline \multirow{2}{*}{\multicolumn{5}{|c|}{$\begin{array}{l}\text { Seeking information offline and subsequently purchasing } \\
\text { products online are. . for my making purchase decision }\end{array}$}} \\
\hline & & & & \\
\hline (PVS1) efficient & $* * *$ & & & \\
\hline (PVS2) useful & 0.720 & & & \\
\hline (PVS3) productive & ***** & & & \\
\hline (PVS4) sensible & 0.702 & & & \\
\hline (PVS5) effective & 0.837 & & & \\
\hline (PVS6) functional & 0.828 & & & \\
\hline (PVS7) entertaining & 0.780 & & & \\
\hline (PVS8) necessary & 0.811 & & & \\
\hline Perceived value of webrooming (PVW) & & 0.867 & 0.853 & 0.537 \\
\hline \multicolumn{5}{|l|}{$\begin{array}{l}\text { Seeking information online and subsequently purchasing } \\
\text { products offline are... for my making purchase decision }\end{array}$} \\
\hline (PVW1) effective & 0.748 & & & \\
\hline (PVW2) useful & 0.721 & & & \\
\hline (PVW3) productive & $* * *$ & & & \\
\hline (PVW4) sensible & 0.733 & & & \\
\hline (PVW5) efficient & 0.747 & & & \\
\hline (PVW6) functional & $* * *$ & & & \\
\hline (PVW7) entertaining & $* * *$ & & & \\
\hline (PVW8) necessary & 0.737 & & & \\
\hline Perceived compatibility $(P C)$ & & 0.853 & 0.910 & 0.772 \\
\hline \multicolumn{5}{|l|}{ Omni-channel shopping } \\
\hline (PC1) is compatible with all aspects with my shopping habits & 0.867 & & & \\
\hline (PC2) fits into my shopping style & 0.876 & & & \\
\hline (PC3) fits well with the way I like to shop & 0.893 & & & \\
\hline $\begin{array}{l}\text { Perceived risk (PR) } \\
\text {. . when making omni-channel purchase decision }\end{array}$ & & 0.733 & 0.849 & 0.652 \\
\hline (PR1) there is a high risk & 0.785 & & & \\
\hline (PR2) it is more likely to suffer loses & 0.849 & & & \\
\hline (PR3) the probability of making a good bargain is small & 0.785 & & & \\
\hline Omni-channel shopping intention (OSI) & & 0.876 & 0.915 & 0.731 \\
\hline (OSI1). . . will use the omni-channel method to buy products & 0.896 & & & \\
\hline $\begin{array}{l}\text { (OSI2)... intend to adopt omni-channel shopping frequently in } \\
\text { the future }\end{array}$ & 0.809 & & & \\
\hline $\begin{array}{l}\text { (OSI3)... will recommend omni-channel shopping to people } \\
\text { around }\end{array}$ & 0.807 & & & \\
\hline $\begin{array}{l}\text { (OSI4) ... will encourage family members, friends and relatives } \\
\text { to use the omni-channel method for shopping }\end{array}$ & 0.903 & & & \\
\hline Note(s): ***: items omitted & & & & \\
\hline
\end{tabular}

Table 2.

The results of assessing the validity and reliability of research's measurements
(PVS1) efficient

(PVS2) useful

0.720

0.702

0.780

(PVS7) entertaining

(PVS8) necessary

Perceived value of webrooming (PVW)

Seeking information online and subse (PVW1) effective

(PVW2) useful

0.733

0.747

$* * *$

(PVW7) entertaining

cossary

Omni-channel shopping

(PC1) is compatible with all aspects with my shopping habits

(PC2) fits into my shopping style

0.876

0.893

0.785

0.849

0.896

0.896

0.807 around

(OSI4) . . will encourage family members, friends and relatives

Note(s): ***: items omitted 


\begin{tabular}{|c|c|c|c|c|c|c|}
\hline Construct & $\begin{array}{l}\text { Omni-channel } \\
\text { shopping } \\
\text { intention }\end{array}$ & $\begin{array}{c}\text { Perceived } \\
\text { compatibility }\end{array}$ & $\begin{array}{c}\text { Perceived } \\
\text { risk }\end{array}$ & $\begin{array}{l}\text { Perceived value } \\
\text { of showrooming }\end{array}$ & $\begin{array}{l}\text { Perceived value } \\
\text { of webrooming }\end{array}$ & \multirow{2}{*}{$\begin{array}{r}\text { Drivers of } \\
\text { omni-channel } \\
\text { shopping } \\
\text { intention }\end{array}$} \\
\hline $\begin{array}{l}\text { Omni-channel } \\
\text { shopping } \\
\text { intention }\end{array}$ & 0.855 & & & & & \\
\hline $\begin{array}{l}\text { Perceived } \\
\text { compatibility }\end{array}$ & 0.540 & 0.879 & & & & 151 \\
\hline Perceived risk & -0.756 & -0.347 & 0.807 & & & \multirow{3}{*}{$\begin{array}{r}\text { Table } 3 . \\
\text { The square root of } \\
\text { AVE and correlation } \\
\text { coefficients between } \\
\text { variables }\end{array}$} \\
\hline $\begin{array}{l}\text { Perceived value } \\
\text { of showrooming }\end{array}$ & 0.830 & 0.452 & -0.757 & 0.792 & & \\
\hline $\begin{array}{l}\text { Perceived value } \\
\text { of webrooming }\end{array}$ & 0.526 & 0.339 & -0.439 & 0.491 & 0.733 & \\
\hline
\end{tabular}

First, the results of the variance inflation factor (VIF) are less than 5, allowing us to confirm that the collinearity between explanatory variables is not a serious problem in the structural model (Hair et al., 2016). It is, therefore, possible to continue the next steps of the evaluation.

As expected, the path coefficients related to the effects between variables in the research model are statistically significant at the $5 \%$ significance level. Notably, the bootstrap test results with 5,000 replicates show that the above coefficients are all different from 0 . Therefore, it can be concluded that the hypotheses from $\mathrm{H} 1$ to $\mathrm{H} 4$ are supported on data. The results of path coefficient analysis are presented in Figure 2.

The results show that perceived value of showrooming has a stronger impact on omnichannel shopping intention $(\beta=0.590)$ than the effect of perceived value of webrooming on omni-channel shopping intention $(\beta=0.184)$. In comparison with these relations, perceived compatibility has a weaker influence on omni-channel shoppers' intention $(\beta=0.171)$. Furthermore, perceived risk has been shown to be an important premise for shopping intention in the omni-channel setting $(\beta=0.685)$. Table 4 indicates the results of testing research hypotheses.

To test the predictive power of endogenous structures - which reflect the value of relationships, the study uses $R^{2}$ values. The $R^{2}$ of omni-channel shopping intention $(0.812)$ is

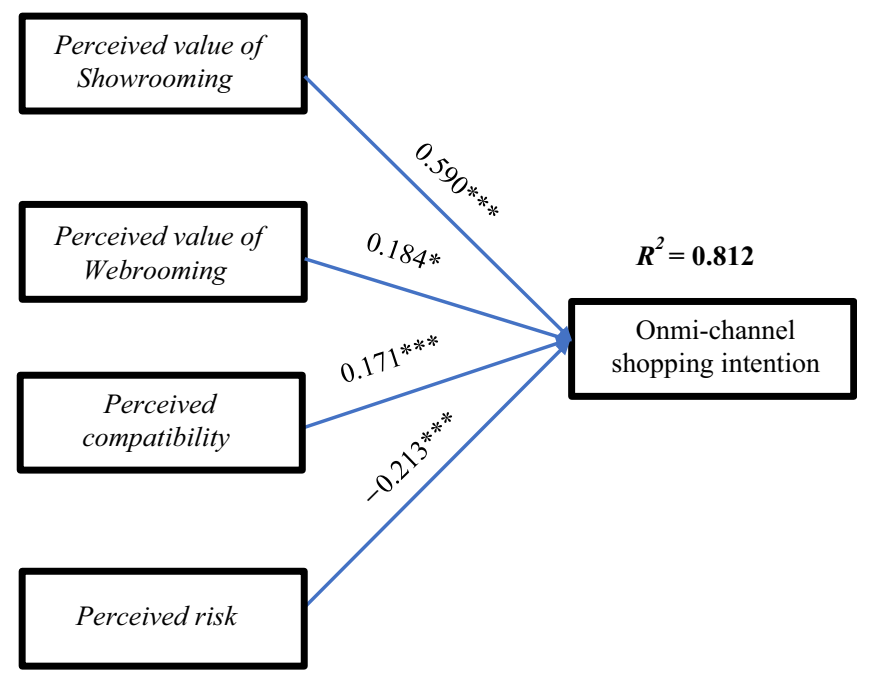

Figure 2. Final PLS-SEM result 
JABES

28,2

152

assessed to be significant, and this value is considered to be quite strong according to many researchers like Henseler et al. (2009). The final results are demonstrated in Figure 2.

\section{Discussion and implications}

\subsection{Discussion on findings}

This research sheds light on the determinants of shopping intention in the context of omnichannel retailing. From the empirical results, there are four major noteworthy points, which will be discussed in this section.

First of all, the positive linkages between perceived value of showrooming as well as webrooming and omni-channel shopping intention were confirmed in this study, which is in line with the research of Kang (2019). Unsurprisingly, the vital role of perceived value in forecasting customer intention behaviours was accepted in the literature (Kleijnen et al., 2007; Jalil et al., 2016). The value perceived by customers results from assessing the benefits and sacrifices through purchasing and using a product or service. When it comes to the context of omni-channel retailing environment, research shopping behaviours of omni-channel customers like showrooming and webrooming could benefit them by providing information useful for making decisions. These findings also are in line with Kwon and Jain's research (2009), which found that consumers with high levels of information seeking were likely to involve in multichannel shopping as compared to those with low levels of information seeking. Consequently, the more value customers perceive through showrooming and webrooming that are characterized as outstanding characteristic of omni-channel shoppers, the more intention they adapt this method for shopping.

Second, the findings suggest that perceived compatibility is positively associated with customers' shopping intention in omni-channel setting, which is in accordance with the work of Shi et al. (2020). To be considered as one of the essential characteristics of innovation, perceived compatibility could appears when customers move from offline channels to online channels because they are more likely to depend on their past shopping experience, with particular channel to evaluate whether they choose to shop by the omni-channel method or not. This is mentioned in some previous studies such as Cook (2014); Piotrowicz and Cuthbertson (2014) in which these scholars suggest the heavy dependence of customers shopping expectation on both their past experiences and preferences. Hence, the more compatibility they perceived when shifting shopping channels, the more intention they have towards omni-channel shopping.

Third, the results further point out that perceived risks negatively predict omni-channel shopping intention. This evidence is consistent with Shi et al.'s study (2020). As mentioned above, besides benefits, customers are aware of risks when buying and using a product or service, evaluating perceived value as well as affecting their shopping intention behaviour. Noticeably, prior research has explained the negative association between perceived risk and customer behaviour in the omni-channel setting by overall assessments of uncertainty as well as potential adversity they incur during the shopping process when regarding nontransparencies, non-uniformity among channels, information insecurity, performance failure (Herhausen et al., 2015; Xu and Jackson, 2019).

Table 4.

The results of testing research hypotheses

\begin{tabular}{lrrcccc}
\hline Hypotheses & Std. $\beta$ & $t$-value & $\begin{array}{c}\text { Research model } \\
95 \% \text { confidence interval }\end{array}$ & $p$-value & VIF & Conclusion \\
\hline H1: PCV $\rightarrow$ OSI & 0.590 & 11.007 & {$[0.482 ; 0.694]$} & 0.000 & 2.716 & Accept \\
H2: PCW $\rightarrow$ OSI & 0.184 & 4.096 & {$[0.066 ; 0.266]$} & 0.036 & 1.368 & Accept \\
H3: PC $\rightarrow$ OSI & 0.171 & 4.600 & {$[0.097 ; 0.243]$} & 0.000 & 1.286 & Accept \\
H4: PR $\rightarrow$ OSI & -0.213 & 4.269 & {$[-0.310 ;-0.112]$} & 0.000 & 2.375 & Accept \\
\end{tabular}


Fourth, it could be concluded from the descriptive analysis, showrooming phenomenon is more popular in the multi-channel retailing setting by comparison with webrooming. This could stem from the common perceptions that online prices are lower than offline (Nesar and Sabir, 2016). However, the gap between showroomers and webroomers in this study is not quite large. Unsurprisingly, many recent researches (Fallon, 2014; Khan, 2020) suggest a few reasons why customers prefer webrooming over showrooming. Particularly, many customers do not want either to pay for shipping or wait for delivery. Furthermore, the results demonstrate the prevalence of research shopping behaviours among millennials (also known as Generation Y) and Generation $Z$ (aged from 18-34). Interestingly, this finding is also found in some previous studies such as Nesar and Sabir (2016); Lachman and Brett (2013). These scholars explain that these group of customers are bored easily and keen on the lookout for new excitement. Therefore, not only are they more likely to invest time and efforts to get product information, compare prices, envision how items would look on them or respond to flash sales or coupon offers, but they also are willing to try new shopping experiences or pay more for uniqueness.

Finally, it is worth closing this section by discussing some key points of empirical results that are different from prior studies. Specifically, by comparison with Shi et al.'s (2020) work, the influences of perceived compatibility and perceived risk on omni-channel shopping intention are not strong. In the context of this study, not only do customers perceive high risk, but they also perceive unclearly the compatibility when shopping among various channels. This leads to the limited roles of these two variables in explaining customers' omni-channel shopping intention in Danang, Vietnam. Moreover, while the empirical findings from Kang (2019) highlight a more powerful effect of webrooming than showrooming on omni-channel shopping intention of customers, there is an opposite result in this research. Seemingly, customers perceive that they were more efficient when showrooming than webrooming, although these phenomena benefit them as well as become prevalent patterns. Naturally, for fashion items that could bring functional, self-expressive and emotional benefits for customers, they still want the tactile, tangible and personal in-store experience.

\subsection{Implications}

This study not only attempts to fill the research gap in the area of customer behaviours among omni-channel retailing environment but also implies some crucial issues about designing effectively retailing channel strategies for retailers.

From a theoretical perspective, comprehending customer perception of the omni-channel concept has been emerging as an important theme in recent literature as well as in practitioners' reports (Chen et al., 2018; Shen et al., 2018). Hence, the meaningful contribution of this study is the involvement in the attractive stream of study. Particularly, by combining the IDT and the prospect theory to identify determinants of shopping intention in an omnichannel retailing environment, this study enriches the current literature on omni-channel shoppers' perception of research shopping behaviours (showrooming and webrooming) and their awareness of compatibility, as well as risks when adopting various channels simultaneously. To the best of my knowledge, the present research is seemingly one of the few studies in the world and the first study in Vietnam to empirically assess the drivers of omni-channel shopping intention, especially mentioning the effects of showrooming and webrooming behaviours. Besides, although there are now sufficient studies on retailing channel strategies, including multi- and omni-channel from retailers' perspective, the question of how to make customers involve themselves in adopting the omni-channel setting still requires an answer (Konuş et al., 2014). Thus, this research not only attempts to answer this question from customers' perspective but also suggest a fruitful area for more behavioural- oriented researchers in Vietnam.

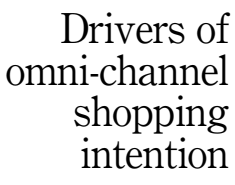

153 
JABES

28,2

From a managerial perspective, this study could offer guidance to retailers or managers about developing a successful omni-channel strategy from a customer point of view. Firstly, by assessing the antecedents of omni-channel shopping intention, retailers could pay special attention to customers' perception of showrooming and webrooming values playing a central role in customer behaviours in the omni-channel setting (Kang, 2018). Particularly, omnichannel consumers use all channels simultaneously like physical stores, internet kiosks, websites, social media, mobile, instead of only adopting one or two channels (Total Retail, 2010). During their purchase process, customers often seek information on one channel but buy products or services from other, which is the so-called "research shopping behaviour" (Fornari et al., 2016). As a result, providing timely, valuable, complete and transparent information could be considered as a good way for retailers to not only increase customer intention of omni-channel shopping but also prevent churn rate during the process of searching and analyzing information before making decisions. Secondly, the compatibility between omni-channel shopping experiences and pervious shopping experiences or habits of customers should be valued as a practical solution for enhancing omni-channel shopping intention. Specifically, Juaneda-Ayensa et al. (2016) explain that the shopping preference and expectation of customers have been shifting along with technology advancements in retailing such as augmented reality, virtual reality or sensory devices, etc. Hence, it is very important for retailers and managers to assure that consumers could perceive the compatibility between technologies utilized in omni-channel retailing and their past shopping experiences, habits or preferences. For instance, the consistency of information as well as the interconnection across various channels are essential to make sure that consumers do not feel confused during the purchasing process. Noticeably, these things are often known as channel integration activities of retailers in the omni-channel literature, by which retailers create and deliver values to customers through optimizing the synergy across channels. Thirdly, empirical results illustrate customer perception of risks in the omni-channel environment would hamper their intent to employ this method for shopping. Prior research shows that perceived related performance, finance or security risks may appear over the omni-channel shopping process due to some problems related to channel transparency, channel uniformity, new technologies or channel convenience (Xu and Jackson, 2019; Shi et al., 2020). This highlights the significance of channel attributes; hence, omni-channel retailers might follow channel strategies to lead to low-risk perception such as enhancing content and process consistency across channels, developing effective personalization strategies. For example, advanced technologies like artificial intelligence (AI), cashierless stores (Amazon Go as an example), services of buy online, pick-up in store (BOPIS) for holiday shopping needs, big data-based analysis systems could be applied to facilitate personalization.

For fashion item purchases that require a strong experiential component, customers could devote their time and efforts to seek product information, alternatives as well as product experiences of other consumers across channels. With the proliferation of fashion retailing market in Vietnam, researching information prior to buying is inevitable, regardless of whether the purchase will be in-store or online. Noticeably, almost all of fashion retailers in Danang have implemented multiple sales channels in which a significant majority of omnichannel retailers currently are chain retailers. That means they have brick-and-mortar system across the country, in addition to non-traditional retail channels. Thus, to gain competitive advantages, it is very important to bring seamless shopping experiences for customers by channel integration activities on dimensions such as products and prices, promotion, transaction information, information access, order fulfilment, customer services, on Zhang et al.'s (2018) suggestion. Indeed, these six aspects cover the entire shopping process. To set in the context of Danang, it is essential for retailers to make interconnections among not only various channels but also other locations. Particularly, visitors could buy items at physical stores in Danang and then return them at the same brand stores in other cities. 
Retailers could encourage customers to pick up and/or return online orders at physical stores to attract additional sales and reduce mailing cost. Besides developing e-commerce, opening showrooms is necessary for customers to see, touch and feel fashion items. Their transaction as well as access information need to be stored into customer database to make sure that every consumer is viewed as the same customer across all of the channels. Consequently, these channels all provide after-sales service for each other. As a tourist attraction, furthermore, retailers in Danang should pay more attention to bringing new excitement for travellers when visiting local stores. Specifically, stores incorporate computer kiosks, so shoppers can directly order out-of-stock sizes or colours and have the purchases sent to their home or anywhere they want. Sensory aspects of retail facilities need to evolve constantly with an effort to retain young shoppers' patronage. Obviously, customers need to be more empowered to effectively control their shopping process under the leverage of technology.

\section{Limitations and future research}

Naturally, this study cannot be without limitations, despite its several interesting findings. Firstly, carried in Danang, Vietnam, and particularly focused on the fashion retailing sector, the research result may be not generalized to other contexts. Hence, future studies could assess this theoretical framework with regard to other categories of products (beauty products, consumer electronics, etc.). Secondly, from a methodological perspective, employing a PLS-SEM model with a small sample appropriate to this research's exploration and mainly depending on the survey method with self-reported data may affect the quality of research data. Therefore, future researches should either adopt other method (such as field experiment, or data mining) to validate better this research model or replicate the research in many areas and even countries, instead of focusing only one geographical location with the aim of increasing generalizability. Finally, this research has not mentioned cultural differences or demographic differences that are critical to predict customer behaviours. Future studies, thus, are suggested to examine the effects of cultural variables or demographic variables in its research context (such as the differences in Generation X and Generation Y behaviours in an omni-channel setting).

\section{References}

Ailawadi, K.L. and Farris, P.W. (2017), "Managing multi-and omni-channel distribution: metrics and research directions", Journal of Retailing, Vol. 93 No. 1, pp. 120-135.

Alalwan, A.A., Dwivedi, Y.K., Rana, N.P. and Algharabat, R. (2018), "Examining factors influencing Jordanian customers' intentions and adoption of internet banking: extending UTAUT2 with risk", Journal of Retailing and Consumer Services, Vol. 40, pp. 125-138.

Aljabri, I.M. and Sohail, M.S. (2012), "Mobile banking adoption: application of diffusion of innovation theory", Journal of Electronic Commerce Research, Vol. 13 No. 4, pp. 379-391.

Anderson, J. and Gerbing, D. (1988), "Structural equation modeling in practice: a review and recommended two-step approach”, Psychological Bulletin, Vol. 103 No. 3, pp. 411-423.

Bernon, M., Cullen, J. and Gorst, J. (2016), “Online retail returns management”, International Journal of Physical Distribution and Logistics Management, Vol. 46 Nos 6-7, pp. 584-605.

Brynjolfsson, E., Hu, Y.J. and Rahman, M.S. (2013), Competing in the Age of Omnichannel Retailing, MIT, Cambridge.

Business Insider Intelligence (2017), "E-commerce will make up 17\% of all US retail sales by 2020- and one company is the main reason", available at: https://www.businessinsider.com/e-commerceretail-sales-2022-amazon-2017-8. 
JABES

28,2

156

Carroll, D. and Guzmán, I. (2015), "The new omni-channel approach to serving customers", Accenture Consulting, available at: https://www.accenture.com/be-en/ /media/Accenture/ConversionAssets/ DotCom/Documents/Global/PDF/Industries_2/accenture-new-omni-channel-approach-servingcustomers.pdf.

Chen, Y., Cheung, C. and Tan, C. (2018), "Omnichannel business research: opportunities and challenges”, Decision Support Systems, Vol. 109, pp. 1-4.

Chin, W.W., Marcolin, B.L. and Newsted, P.R. (2003), "A partial least squares latent variable modeling approach for measuring interaction effects: results from a Monte Carlo simulation study and an electronic-mail emotion/adoption study", Information Systems Research, Vol. 14 No. 2, pp. 189-217.

Chiou, J.S., Wu, L.Y. and Chou, S.Y. (2012), "You do the service but they take the order", Journal of Business Research, Vol. 65 No. 7, pp. 883-889.

Christensen, C. and Raynor, M. (2003), The Innovator's Solution: Creating and Sustaining Successful Growth, Harvard Business Review Press, Boston.

Cook, G. (2014), "Customer experience in the omni-channel world and the challenges and opportunities this presents", Journal of Direct, Data and Digital Marketing Practice, Vol. 15 No. 4, pp. 262-266.

De Kerviler, G., Demoulin, N.T. and Zidda, P. (2016), "Adoption of in-store mobile payment: are perceived risk and convenience the only drivers?", Journal of Retailing and Consumer Services, Vol. 31, pp. 334-344.

Dwivedi, Y.K., Rana, N.P., Jeyaraj, A., Clement, M. and Williams, M.D. (2019), "Re-examining the unified theory of acceptance and use of technology (UTAUT): towards a revised theoretical model", Information Systems Frontiers, Vol. 21 No. 3, pp. 719-734.

Falk, T., Schepers, J., Hammerschmidt, M. and Bauer, H.H. (2007), "Identifying cross-channel dissynergies for multichannel service providers", Journal of Service Research, Vol. 10 No. 2, pp. 143-160.

Fallon, N. (2014), "Why 'webrooming' could bring customers back into stores”, Business News Daily, available at: http://www.sviluppareaffari.it/vendereoggi/webrooming.pdf.

Flavián, C., Gurrea, R. and Orús, C. (2016), "Choice confidence in the webrooming purchase process: the impact of online positive reviews and the motivation to touch", Journal of Consumer Behaviour, Vol. 15 No. 5, pp. 459-476.

Fornari, E., Fornari, D., Grandi, S., Menegatti, M. and Hofacker, C. (2016), "Adding store to web: migration and synergy effects in multi-channel retailing", International Journal of Retail and Distribution Management, Vol. 44 No. 6, pp. 658-674.

Fornell, C. and Larcker, D.F. (1981), "Evaluating structural equation models with unobservable variables and measurement error", Journal of Marketing Research, Vol. 18 No. 1, pp. 39-50.

Hair, J.F. Jr, Sarstedt, M., Hopkins, L. and Kuppelwieser, G.V. (2014), "Partial least squares structural equation modeling (PLS-SEM) an emerging tool in business research", European Business Review, Vol. 26 No. 2, pp. 106-121.

Hair, J.F. Jr, Hult, G.T.M., Ringle, C. and Sarstedt, M. (2016), A Primer on Partial Least Squares Structural Equation Modeling (PLS-SEM), Sage Publications, Los Angeles.

Hair, J.F. Jr, Sarstedt, M., Ringle, C.M. and Gudergan, S.P. (2017), Advanced Issues in Partial Least Squares Structural Equation Modelling, Sage Publications, Los Angeles.

Henseler, J., Ringle, C. and Sinkovics, R. (2009), "The use of partial least squares path modeling in international marketing", in Sinkovics, R. and Ghauri, P. (Eds), New Challenges to International Marketing (Advances in International Marketing), Emerald Group Publishing Limited, Bingley, Vol. 20, pp. 277-319.

Herhausen, D., Binder, J., Schoegel, M. and Herrmann, A. (2015), "Integrating bricks with clicks: retailer-level and channel-level outcomes of online-offline channel integration", Journal of Retailing, Vol. 91 No. 2, pp. 309-325. 
Jalil, N.A.A., Fikry, A. and Zainuddin, A. (2016), "The impact of store atmospherics, perceived value, and customer satisfaction on behavioural intention", Procedia Economics and Finance, Vol. 37, pp. 538-544.

Juaneda-Ayensa, E., Mosquera, A. and Sierra Murillo, Y. (2016), "Omnichannel customer behavior: key drivers of technology acceptance and use and their effects on purchase intention", Frontiers in Psychology, Vol. 7, p. 1117.

Kahneman, D. and Tversky, A. (1979), "Prospect theory: an analysis of decision under risk", Econometrica, Vol. 47 No. 2, pp. 363-391.

Kang, J.Y.M. (2018), "Showrooming, webrooming, and user-generated content creation in the omnichannel era", Journal of Internet Commerce, Vol. 17 No. 2, pp. 145-169.

Kang, J. (2019), "What drives omnichannel shopping behaviors?", Journal of Fashion Marketing and Management: International Journal, Vol. 23 No. 2, pp. 224-238.

Kazancoglu, I. and Aydin, H. (2018), “An investigation of consumers' purchase intentions towards omni-channel shopping”, International Journal of Retail and Distribution Management, Vol. 46 No. 10, pp. 959-976.

Khan, H. (2020), "Consumers are showrooming and webrooming your business, here's what that means and what you can do about it", available at: https://www.shopify.com/retail/119920451consumers-are-showrooming-and-webrooming-your-business-heres-what-that-means-and-whatyou-can-do-about-it.

Kim, E., Park, M.C. and Lee, J. (2017), "Determinants of the intention to use buy-online, pickup in-store (BOPS): the moderating effects of situational factors and product type", Telematics and Informatics, Vol. 34 No. 8, pp. 1721-1735.

Kleijnen, M., De Ruyter, K. and Wetzels, M. (2007), “An assessment of value creation in mobile service delivery and the moderating role of time consciousness", Journal of Retailing, Vol. 83 No. 1, pp. 33-46.

Konuş, U., Neslin, S.A. and Verhoef, P.C. (2014), "The effect of search channel elimination on purchase incidence, order size and channel choice", International Journal of Research in Marketing, Vol. 31 No. 1, pp. 49-64.

Kumar, V. and Venkatesan, R. (2005), "Who are the multichannel shoppers and how do they perform?: correlates of multichannel shopping behavior", Journal of Interactive Marketing, Vol. 19 No. 2, pp. 44-62.

Kwon, K.N. and Jain, D. (2009), "Multichannel shopping through nontraditional retail formats: varietyseeking behavior with hedonic and utilitarian motivations", Journal of Marketing Channels, Vol. 16 No. 2, pp. 149-168.

Lachman, M.L. and Brett, D.L. (2013), Generation Y: Shopping and Entertainment in the Digital Age, Urban Land Institute, Washington, DC.

Limayem, M., Hirt, S.G. and Cheung, C.M. (2007), "How habit limits the predictive power of intention: the case of information systems continuance", MIS Quarterly, Vol. 31 No. 4, pp. 705-737.

Liu, L., Feng, L., Xu, B. and Deng, W. (2020), “Operation strategies for an omni-channel supply chain: who is better off taking on the online channel and offline service?", Electronic Commerce Research and Applications, Vol. 39, p. 100918.

Mau, S., Cvijikj, I.P. and Wagner, J. (2015), "From research to purchase: an empirical analysis of research-shopping behaviour in the insurance sector", Zeitschrift für die Gesamte Versicherungswissenschaft, Vol. 104 No. 5, pp. 573-593.

Moore, G.C. and Benbasat, I. (1991), "Development of an instrument to measure the perceptions of adopting an information technology innovation”, Information Systems Research, Vol. 2 No. 3, pp. 192-222.

Nesar, S. and Sabir, L.B. (2016), "Evaluation of customer preferences on showrooming and webrooming: an empirical study", Al-Barkaat Journal of Finance and Management, Vol. 8 No. 1, pp. 50-67.

\section{Drivers of omni-channel shopping intention}


JABES

28,2

158

Nunes, P.F. and Cespedes, F.V. (2003), "The customer has escaped", Harvard Business Review, Vol. 81 No. 11, pp. 96-105.

Ostrom, A.L., Parasuraman, A., Bowen, D.E., Patrício, L. and Voss, C.A. (2015), "Service research priorities in a rapidly changing context", Journal of Service Research, Vol. 18 No. 2, pp. 127-159.

Pan, Y., Gao, L. and Wang, F.H. (2009), "Chinese consumer purchasing behavior research-from the perspective of confucian values and lifestyles", China Industrial Economics, Vol. 29 No. 9, pp. 77-86.

Pauwels, K., Leeflang, P.S., Teerling, M.L. and Huizingh, K.E. (2011), "Does online information drive offline revenues?: only for specific products and consumer segments!", Journal of Retailing, Vol. 87 No. 1, pp. 1-17.

Piotrowicz, W. and Cuthbertson, R. (2014), "Introduction to the special issue information technology in retail: toward omnichannel retailing", International Journal of Electronic Commerce, Vol. 18 No. 4, pp. 5-16.

Rogers, E. (2010), Diffusion of Innovations, Simon and Schuster, New York, NY.

Shapiro, S.L., Reams, L. and So, K.K.F. (2019), "Is it worth the price? The role of perceived financial risk, identification, and perceived value in purchasing pay-per-view broadcasts of combat sports", Sport Management Review, Vol. 22 No. 2, pp. 235-246.

Shen, X.L., Li, Y.J., Sun, Y. and Wang, N. (2018), "Channel integration quality, perceived fluency and omnichannel service usage: the moderating roles of internal and external usage experience", Decision Support Systems, Vol. 109, pp. 61-73.

Shi, S., Wang, Y., Chen, X. and Zhang, Q. (2020), "Conceptualization of omnichannel customer experience and its impact on shopping intention: a mixed-method approach", International Journal of Information Management, Vol. 50, pp. 325-336.

Song, Y., Guo, S. and Zhang, M. (2019), “Assessing customers' perceived value of the antihaze cosmetics under haze pollution”, The Science of the Total Environment, Vol. 685, pp. 753-762.

Sopadjieva, E., Dholakia, U.M. and Benjamin, B. (2017), "A study of 46,000 shoppers shows that omnichannel retailing works”, Harvard Business Review, available at: hbr.org/2017/01/a-studyof-46000-shoppers-shows-that-omnichannel-retailing-works (accessed 25 June 2017).

Tojib, D. and Tsarenko, Y. (2012), "Post-adoption modeling of advanced mobile service use", Journal of Business Research, Vol. 65 No. 7, pp. 922-928.

Total Retail (2010), "The omnichannel shopper: anytime, anyplace, anywhere", available at: https:// www.mytotalretail.com/article/the-omnichannel-shopper-anytime-anyplace-anywhere/all/.

Van der Heijden, H., Verhagen, T. and Creemers, M. (2003), "Understanding online purchase intentions: contributions from technology and trust perspectives", European Journal of Information Systems, Vol. 12 No. 1, pp. 41-48.

Verhoef, P.C., Neslin, S.A. and Vroomen, B. (2007), "Multichannel customer management: understanding the research-shopper phenomenon", International Journal of Research in Marketing, Vol. 24 No. 2, pp. 129-148.

Verhoef, P.C., Kannan, P.K. and Inman, J.J. (2015), "From multi-channel retailing to omni-channel retailing: introduction to the special issue on multi-channel retailing", Journal of Retailing, Vol. 91 No. 2, pp. 174-181.

Voss, K.E., Spangenberg, E.R. and Grohmann, B. (2003), "Measuring the hedonic and utilitarian dimensions of consumer attitude", Journal of Marketing Research, Vol. 40 No. 3, pp. 310-320.

Won Jeong, S., Fiore, A., Niehm, L. and Lorenz, F. (2009), "The role of experiential value in online shopping", Internet Research, Vol. 19 No. 1, pp. 105-124.

$\mathrm{Xu}, \mathrm{X}$. and Jackson, J.E. (2019), "Examining customer channel selection intention in the omni-channel retail environment", International Journal of Production Economics, Vol. 208, pp. 434-445. 
Zhang, M., Ren, C., Wang, G.A. and He, Z. (2018), "The impact of channel integration on consumer responses in omni-channel retailing: the mediating effect of consumer empowerment", Electronic Commerce Research and Applications, Vol. 28, pp. 181-193.

\section{Corresponding author}

Thi Hieu Hanh Truong can be contacted at: hanhtth@due.edu.vn
Drivers of omni-channel shopping intention

For instructions on how to order reprints of this article, please visit our website: www.emeraldgrouppublishing.com/licensing/reprints.htm Or contact us for further details: permissions@emeraldinsight.com 